\title{
EFFICACIOUS PROTOTYPING FOR EARLY STAGE INDUSTRIAL DESIGN: UNDERSTANDING WHAT MATTERS IN PROTOTYPING TO MAKE PROTOTYPING MATTER MORE
}

\author{
Raunak MAHTANI, Kelly UMSTEAD and Carolina GILL \\ North Caroline State University, USA
}

\begin{abstract}
Prototypes are integral tools designers, engineers and other creatives utilise for developing solutions. In the broadest sense, the term 'prototype' may mean different things, and be the means to different ends. Prototypes play a significant role in idea generation in the early stages of design projects and can act as a catalyst for innovation in a collaborative setting. Successful prototypes are thoughtful about their purpose and context of usage. This makes it important to understand how attributes of the prototype and the prototyping process affect the design process.

The landscape of design is evolving- increasingly efficient and sophisticated technology is used in the prototyping process. Multiple stakeholders and end-users are involved throughout the design process, which makes collaborative prototyping and co-creation a valuable activity. The objective of this project is to utilise such an understanding to improve the tools and technologies to better support design teams through their process. Secondary source research and semi-structured interviews with designers have been conducted to understand the challenges faced and to investigate the attributes of prototyping such as modality (physical versus digital), fidelity (high versus low), materials and processes used, effort and time spent, and their effect on the process. Throughout a dynamic design process, prototyping can be a part of different phases of a project, can involve different sets of stakeholders, and can need to perform in different ways. A key theme to the findings has been that 'economy' and 'effectiveness' are broad needs from the prototyping process, and that specific needs what is meant by economy and effectiveness - can vary across different scenarios.
\end{abstract}

Keywords: Prototyping, industrial design, product design, product development, engineering, technology, collaboration

\section{INTRODUCTION}

'Trying it out' has been a motto integral to the progress of humankind since its very beginning. Creative experimentation always holds the excitement of future possibilities waiting to be unveiled when we try to innovate. Prototyping, the formally named phenomenon, brings the same wonder and uncertainty to the design process. It is where the present meets the future, the abstract and concrete intertwine in a dance, and potential realities flicker into existence.

Prototyping in one way or another is a part of every design process: we prototype physical products, software, systems, services and experiences [1]. We prototype throughout the process: from early stage models which could utilise even found objects taped together to form a useful prototype to higher fidelity models close to the production phase. We prototype to solve problems and to understand them: prototypes can be used to operationalise hypotheses in research phases of projects [1]. Not much limits what a prototype can be. Houde and Hill argue that even a brick can be a prototype, depending on how it's used and what question it tries to answer [2].

The prototype is a transient object which evolves and provides feedback to the designers through their process. Donald Schon talks about design as being a reflective conversation with the 'materials' of a situation, describing it as a process where the actors are in constant transaction with the design situation, responding to its demands and possibilities which they in turn help to create [3]. This suggests how seamlessly what we experience, build and envision interact with and affect each other. 
Considering how central a role prototyping plays in the design process, and the abundance of research pointing to how it can affect process and outcome, it is important to be thoughtful about how designers' prototype and how to utilise them as effectively as possible.

Particularly in early stages of the design process, prototypes are known to be valuable in informing brainstorming and solution development. This project aims at understanding what prototyping means to different designers, the different ways in which early stage prototyping informs the design process, and the challenges faced by professional design teams in effectively prototyping for their projects. The goal of this project is to develop a wider understanding of the problem space, and to develop solutions and prototyping tools in line with these needs.

Secondary source research was carried out for this project by reviewing literature, web articles and blog posts from the domains of product design, industrial design, design engineering, design management, human computer interaction and design studies. Semi-structured interviews with six industrial design professionals in varying professional roles were carried out.

\section{A BROAD UNDERSTANDING OF PROTOTYPING}

Reviewing writing from industry and academia, one gets the sense of how broad and fluid the term prototyping is, and the different meanings it can hold. Michael Schrage defines prototyping in three ways. As a 'hypothesis' the prototype is a potential future being tested out, a question being raised. As a 'marketplace', a prototype affords the discussion, negotiation and exchange of value. As a 'playground', a prototype lets the rules be relaxed and allows for an atmosphere of imagination and play, where uncertainty can be beneficial and lead to success [4]. As a hypothesis, prototypes can be used to test different aspects of the design - the role, implementation and look/feel - each of which can be tested individually across prototypes or in combinations within integrated prototypes [2]. Donald Schon talks about the activity of design as a 'reflective conversation with the materials of the situation' [3], a definition which seems to almost diffuse the boundary between prototyping and other design activities. Echoing this view, an interviewee, a designer at a technology firm described prototyping as 'where the brain space meets the head space'. Louise Valentine describes it as an uncontrolled extravaganza of the mind, clarifying that the process is not mindless, but should not be bound by certainty [5]. While there is certainly a benefit to the uncertainty and wonder of the prototyping process, it can be a tool which provides a level of security for later stages of a project for design managers: one interviewee described it as an 'insurance policy' against future risks and costs, while another called it a tool to assess and consequently build investment in a project or concept.

One of the reasons why even prototypes are so broad by definition is that the design industry is significantly evolving right now. Elizabeth Sanders recognises four significant changes in design: a shift in the focus of design, the rise of creative activity for non-designers, interest by business people in design thinking and the obsession with co-creation by all kinds of people [6]. The shift of focus, she says, means that designers are defined less based on the objects being designed and more based on the purpose being designed for: design for experience, design for service, design for innovation, etc. This can mean that objects that are prototyped aren't always physical objects. Products, software, services, policies, interactions and research, all can be prototyped [1]. Designing for such varying purposes, coupled with the rising trend of collaborative work and co-creation, has led to the rise of newer prototyping methodologies like storytelling, participatory prototyping, cultural probes and empathy probes [6]. Michael Schrage argues that prototypes create an ecology for collaboration and that the new challenge for designers will be to figure out how to design the prototyping process and how the culture and environments will be best managed [7]. The significance of prototyping in a collaborative context was reflected in an interviewee's comment that prototypes are a conduit for ideas in such a setting. Yet, in collaborative projects, there can be differences between values of different disciplines and between the content the disciplines tend to work with - analytic vs. synthetic, symbolic vs. real [8]. These differences can lead to different expectations from the prototyping process. In this light, prototypes themselves are like a product which needs to cater of the needs to its users and context [9].

\section{MINDS SHAPE PROTOTYPES SHAPE MINDS}

In line with Schon's understanding of design as a reflective process, the exchange of action and information between the designer and prototype can be cyclic and iterative. This concept is well compatible with Kolb's Experiential Learning Theory [10], which models active learning as a process in which one cycles between concrete learning, reflective observation, abstract conceptualisation and 
active experimentation. It has been speculated that physical prototyping reduces cognitive load on the designer's mind, increasing availability of attention resources to detect and fix errors [11]. The behavioural economics principle of 'sunk cost' is also applicable in the case of prototyping. The more time, effort and cost going into working on a prototype, the more likely one is to be fixated to the associated solution [12]. For example, a study found that as Computer Aided Design (CAD) models became more detailed during the course of a project, there was a strong disincentive to make major changes to them [12].

It is also worth considering the inspirational and motivational benefits of prototyping. Early stage prototyping is found to strengthen beliefs about creative abilities and allow teams to reframe failures as opportunities for learning [13]. A design manager who was interviewed reflects on his experience of prototyping as an 'emotional journey' seeing a solution come to life.

\section{NEED FOR EFFICACY AND ECONOMY}

A major theme and understanding from this study has been that there are two central needs from the prototyping process: efficacy and economy. What is meant by efficacy and economy varies across different scenarios, depending on the purpose of the prototyping activity, the constraints of the project and the collaborators/stakeholders involved in the activity.

Prototypes being of an adequate fidelity is important through early stage design. When prototyping is a tool to support brainstorming and conceptualisation, it needs to facilitate divergent exploration. Rosan Chow through her study on design methods finds that low fidelity prototypes at early stages create a point of departure which allows for more open-ended exploration [14]. People are also found to be more likely to respond to constructive feedback to rough models of concepts [1]. As an outward realisation/manifestation of the concept in the designer's mind, it is important that the prototyping method or tool does not circumscribe thinking - encouraging designers to design in one way over another. Prototypes offer feedback in different forms, both while they are being made and after; haptic feedback, visual feedback, and where applicable, even auditory, gustatory and olfactory feedback. Efficacy also means receiving the right kinds of feedback from the process based on the needs from the activity. For example, a freelance design consultant who was interviewed, reflecting on their numerous mechanism-based projects indicated that it is important to them that the prototypes represent tactile feeling, ergonomics, material hardness, visual scale and proportion of the design. These are some factors that indicate the efficacy needed from prototyping.

Economy is a constant driver, especially in the context of the industry, attributed to budget and time constraints, client expectations, and financial costs. Ease of integration of created prototypes into later stages of the design process can be invaluable in such a context. Digital CAD based tools have a strong advantage in this sense [15]. The need for economy can mean trying to gain as much value from one prototype or set of prototypes as possible: a freelance consultant interviewed indicated that their clients often expect or request that most of the 'design work' be done while CAD modelling and minimum physical models/3D prints be made. Another interviewee, a junior concept designer at a power tool manufacturing company described how parts of 3D printed prototypes are often cut off, with new replacement parts added, in order to utilise as much of the initial print as possible. The need for economy can also make it challenging to prototype novel experiences combining electronic hardware and software experiences. Such cases can be difficult to prototype without significant investment into the implementation of the concepts [16].

\subsection{Physical or digital prototyping?}

In the light of the discussion about efficacy and economy, more traditional, physical methods of prototyping and more modern, digital methods can have competing attributes. Physical model building is known to uncover non-idealities of the real world for engineering design students, allowing for a comparison between one's conceptual model and the real behaviour, and is also known to reduce design fixation [11, 17]. Physical models are known to supplement the designers' mental models and lead them to higher quality ideas [12].

Digital CAD tools, while allowing for advanced visualisation and communication, negatively impact the design process by circumscribing and bounding ideas and lead to premature fixation [18]. At the same time, the 'dimensional truth' maintained by the CAD model - as described by a design manager interviewee - saves time and money as projects move into later stages of prototyping and production. Digital design tools also allow for easy documentation, remote sharing and collaboration, and easy 
editing [15]. These are some of the reasons for which digital prototyping and 3D printing are given such a strong preference in the industry.

The variation in the attributes of different methods can make it necessary for there to be a trade-off or compromise when choosing between methods, causing a designer interviewee to wish for in-betweens which combine attributes of different methods.

\subsection{Challenges of prototyping when collaborating}

The needs from prototyping in a collaborative context can be more complex. Collaborators from different disciplines can have varying expectations from the prototyping process: one interviewee indicated challenges when low fidelity foam core models intended to communicate a concept unavoidably call attention to bad craft related details in meetings with collaborators. Another interviewee described difficulties communicating and visualising concepts for 3D physical products in an inter-disciplinary setting, exacerbated by the difference in the nature of verbal communication and visualisation skills across different disciplines. Creating a shared understanding is in general one of the most challenging aspects of collaboration [19]. Collaborative design meetings can bring with them the expectation of significant creative progress made through the course of the meeting. Most contemporary methods and tools allow teams to create prototypes which are 'static' and require some significant effort to alter. An interviewee indicated a wish for prototyping tools which would allow for quick changes and iterations during the course of a collaborative meeting.

\section{REFLECTION AND DISCUSSION}

This study has been a major learning experience in multiple ways. It has informed multiple directions of potential needs to address in terms of improving prototyping tools and technologies: the need for cost effective evaluation of design concepts through prototypes which provide the right kinds of feedback, the need for effective visualisation and communication of design concepts, the need for more dynamic forms of prototyping which allow for quicker iterations and changes, and the need for economical ways to prototype novel experiences involving electronic hardware and software.

It has been an opportunity of major learning for the student investigator in terms of their own prototyping process and expanded the boundaries of what a prototype can be for them, and the ways in which it can be used. With a broad understanding in place, prototyping can seem like it relates deeply to almost every activity - small or big - within the design process. The awareness this brings to their process is invaluable.

From a teaching perspective, this study re-iterates the need to encourage design and engineering students to thoroughly consider the purpose they are prototyping for, for any given project, and to design the prototype accordingly. It also suggests that it would be beneficial for prototyping courses in design programmes to expand the discussion beyond model-making and workshop tools, to the planning and 'design' of the prototyping process for any given project. This would mean enabling students to answer questions like: what is the purpose of the prototype being made? who are the people interacting with the prototype, and how can the prototype be designed with them in mind? how is this choice of prototyping method influencing the team's design decisions? Such a learning experience could be a valuable bridge between traditional prototyping education and studio education, enabling students to best utilise prototyping, an aspect of the design process which is so central and deeply connected with other aspects.

A big challenge through this project has been to seek secondary source information about the industry with regards to the topic, since subjects of most research studies found have been students. Being a designer, it has been a challenge for the student investigator to be aware of their own biases and point of view, and not letting them affect project outcome. More generally, it has also been a challenge to synthesize insights of a problem space that is very broad, open ended and is rapidly evolving at the present time. Considering the different ways in which prototyping is done and the purposes it is done for, there can be an overlap between attributes of different methods and between the purposes of the prototype, which makes synthesis difficult. Although, that is also what has made this project exciting!

\section{REFERENCES}

[1] Stappers P.J. Prototypes as a Central Vein for Knowledge Development. In Prototype: Craft in the Future Tense, Prototype: Design and Craft in the 21st Century, June 2010, (Bloomsbury Academic, Great Britain). 
[2] Houde S. and Hill C. What do prototypes prototype. Handbook of Human Computer Interaction, 1997.

[3] Schön D. Designing as reflective conversation with the materials of a design situation.

Knowledge-Based Systems, 1992, 5(1),3-14.

[4] Schrage M. Crafting Interactions: The Purpose and Practice of Serious Play. In Prototype: Craft in the Future Tense, Prototype: Design and Craft in the 21st Century, June 2010, (Bloomsbury Academic, Great Britain).

[5] Valentine L. Prototype: Design and Craft in the 21st Century. In Prototype: Craft in the Future Tense, June 2010, (Bloomsbury Academic, Great Britain).

[6] Sanders E. Prototyping for the Design Spaces of the Future. In Prototype: Craft in the Future Tense, Prototype: Design and Craft in the 21st Century, June 2010, (Bloomsbury Academic, Great Britain).

[7] Schrage M. SERIOUS PLAY: The Future of Prototyping and Prototyping the Future. Design Management Journal (Former Series), 2000, 11(3),50-7.

[8] Owen C. Design Thinking: Notes on its Nature and Use. Design Research Quarterly, 2007, 2(1).

[9] Gill C., Sanders E. and Shim S. Prototypes as Inquiry, Visualisation and Communication. In Thirteenth international Engineering and Product Design Education Engineering and Product Design Education, DS 69: Proceedings of E\&PDE 2011, the 13th International Conference on Engineering and Product Design Education, London, UK, 08.-09.09.2011, September 2011, 672677 London, UK).

[10] Experiential Learning (Kolb): https://www.learning-theories.com/experiential-learningkolb.html[Accessed on 2018, September] (2007).

[11] Youmans R.J. The effects of physical prototyping and group work on the reduction of design fixation. Design Studies, 2011, 32(2),115-38.

[12] Viswanathan V. and Linsey J. Design Fixation in Physical Modelling: An Investigation on the Role of Sunk Cost. In ASME 2011 International Design Engineering Technical Conferences \&amp; Computers and Information in Engineering Conference, IDETC/CIE 2011, August 29-31, 2011, 119-130.

[13] Gerber E. and Carroll M. The psychological experience of prototyping. Design Studies, 2012, $33(1), 64-84$.

[14] Chow R. The Rip+Mix Method and Reflection on its Prototypes. In Prototype: Craft in the Future Tense, Prototype: Design and Craft in the 21st Century, June 2010, (Bloomsbury Academic, Great Britain).

[15] Miller A. Digital vs. Physical: why designing in digital beats traditional methods every time. : http://www.eurekamagazine.co.uk/design-engineering-features/technology/digital-vs-physicalwhy-designing-in-digital-beats-traditional-methods-every-time/166109/ [Accessed on 2018, October] (2017).

[16] Gill S. Computer-Embedded Design: Paipr Prototyping. In Prototype: Craft in the Future Tense, Prototype: Design and Craft in the 21st Century, June 2010, (Bloomsbury Academic, Great Britain).

[17] Lemons G., Carberry A., Swan C., Jarvin L. and Rogers C. The benefits of model building in teaching engineering design. Design Studies, 2010, 31(3),288-309.

[18] Robertson B.F. and Radcliffe D.F. Impact of CAD tools on creative problem solving in engineering design. CAD Computer Aided Design, 2009, 41(3).

[19] Piirainen K., Kolfschoten G. and Lukosch S. Unravelling Challenges in Collaborative Design: A Literature Study. In International Conference on Collaboration and Technology, Groupware: Design, Implementation, and Use, (Springer, Berlin, Heidelberg). 